\section{A Simplified Method For Modifying TEM Copper Grids For Use With The Small Angle Cleavage Technique}

\section{Scott D. Walck, Wright Laboratory, Wright Patterson AFB}

The Small Angle Cleavage Technique (SACT) developed by John McCaffrey is an extremely easy and cost-effective technique for producing superior cross sectional TEM samples from semiconductor and other single crystal materials. ${ }^{1-3}$ In the original technique, a special jig is required to be made in order to make two cuts in a $2 \times 0.5 \mathrm{~mm}$ slotted copper TEM grid to create vertical tabs to mount the cleaved samples. This jig is not commercially available and the actual cutting and bending of the grids require a significant amount of manual dexterity. (Fat fingered fellows, like myself, need not apply.) Early on, John proposed a design for a commercial grid that could easily be bent into the required shape with no cutting, but the electron microscopy supply houses passed on the idea. Until now, microscopists wanting to experiment with the technique had to invest in the cost of having one of these jigs made. A new method for making the mounting grids is described below which uses a Veco $2 \times 1$ $\mathrm{mm}$ slotted grid with a handle that is specially folded to create the vertical tab required for the SACT samples. ${ }^{4}$

Tape a Post-it note to the bottom of a microscope glass slide with the sticky side out. Then position the slide under a stereomicroscope such that the edge of the slide is visible in the field of view. The Post-it note will keep the slide from moving around. Place a Veco HDL2 $\times 1-\mathrm{Cu}$ grid on the glass slide with the handle over the edge of the glass slide, as shown in Fig. 1. Bend the handle up over into the slot area of the grid as shown in Fig. 2. Be careful to bend the handle once and make it perpendicular to the long axis of the slot. Rotate the grid and align the bottom of the notched region of the handle with the edge of the microscope slide as shown in Fig. 3. At this point, you have a choice in the way in which you make the vertical mounting tab. If you bend the tab down through the slot and along the edge of the glass slide, the grid will have greater stability, but the vertical tab will be smaller. Also, when the sample is mounted, the small step between the grid and the folded handle will have a tendency for the sample to point downward into the hole of the grid. This risks the possibility of damaging a mounted sample during handling. If you bend the tab up, then the vertical tab is larger in height, but the grid is not as stable. In either case, after the bend, straighten the tabs with a pair of tweezers by squeezing. It is a little easier to see during mounting the sample if the tab is just off from the perpendicular. You can adjust this while squeezing the tab. I prefer to bend the tab up because the sample can be mounted in the corner that is made by the vertical tab and the horizontal surface of the handle and it is protected somewhat by the thickness of the copper grid and the handle. Because I bend the handles up and because I don't flip them to a particular side, i.e., dull or shiny side of the grid, I end up with about the same number of left-handed formed grids as right-handed ones. If you care about this, then you will need to flip the grids to the same side before bending and always bend them in the same way.

Figure 4 shows a sample mounted on a folded HDL2x1-Cu grid Unlike the cut grids, the folded Veco grids give reproducible geometry
This has an added advantage of minimizing the search time to find the thin area when a new sample is put into the TEM if the mounted samples are oriented the same way each time they are inserted in the TEM stage. John's technique for applying a small amount of epoxy on the vertical tab is to dip the tips of his very sharp tweezers into the mixed epoxy and just touch the epoxy to the vertical tab. ${ }^{5}$ It is important that the epoxy used is viscous and does not flow along the sample's surface. The folded SACT grids can be further stabilized in terms of rigidity if a small dollop of epoxy is also placed along the folded grid handle and the grid. The epoxy will flow underneath the grid handle and anchor the handle to the grid after curing. If care is taken so that this epoxy does not go onto the portion of the handle that extends into the slot of the grid, then that portion of the grid handle can still be bent slightly up or down giving a boost to the second tilt axis of a double-tilt TEM stage. For example, if a typical semiconductor material with a growth direction of [100] is placed in the double-tilt stage with this direction perpendicular to the rod axis, i.e., the sample is pointing in the direction of the rod, then both the [001] and [010] zones can be reached by bending this tab. Of course, the sample would have to be taken out of the microscope between reaching these zones in order to bend the tab if both zones are to be examined.

John periodically puts two samples on a single grid. If a second notch was on the opposite side of the handle, this could be a possibility for the handled grids also. Of course, the grid manufacturers would need to become interested in producing such a grid. As a note in closing, tabbed grids without the notch can also be used by cutting the tab at the appropriate place with a very sharp pair of scissors or knife, but the predefined fold lines of the Veco grids allow the SACT grids to be made very quickly. From start to finish, I can bend a grid into shape in about 35 seconds once the stereomicroscope is set up and a supply of grids are dumped onto the slide.

1. J.P. McCaffrey, Ultramicroscody, 38, p. 149, 1991.

2. J.P. McCaffrey, Specimen Preparation for Transmission Electron Microscopy III. Materials Research Society Symposium Proceedings., Vol 254, p. 109, 1992.

3. John P. McCaffrey, Microscopy Research and Technique, 24, p. 180, 1993.

4. The tabbed Veco grids are available through Electron Microscopy Sciences, 321 Morris Road, Box 251, Fort Washington, PA 19034, phone: 1-800-523-5874 or Ernest F. Fullam, Inc, 900 Albany Shaker Rd, Latham, NY, 12110-1491, phone: 1-800833-4024. They are the only suppliers of the Veco grids which have the little notched area on the handle that $I$ have found.

5. The silver epoxy that is used for mounting samples is Epo-Tek H-22 from Epoxy Technology, Inc. 14 Fortune Drive, Billerica, MA 01821, phone: (508) 667-3805

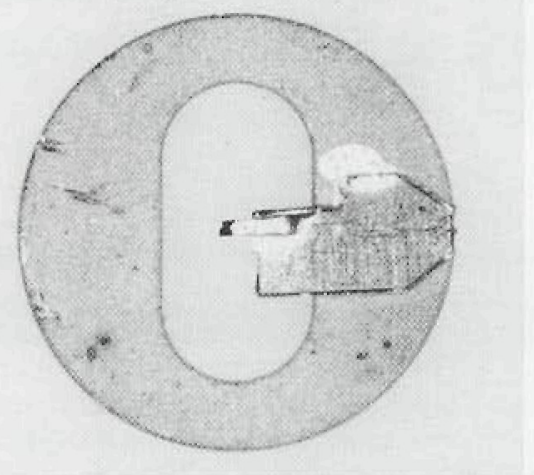

Figure 4: Photograph of a mounted SACT sample on the modified Veco grid.

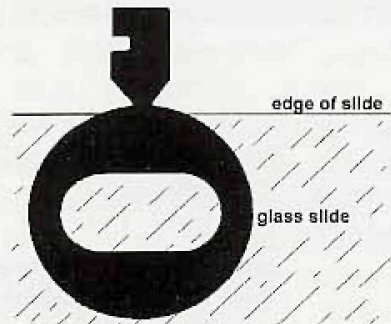

Figure 1: HDL2x1-Cu Veco slotted TEM grid with handle position over the edge of the microscope slide.

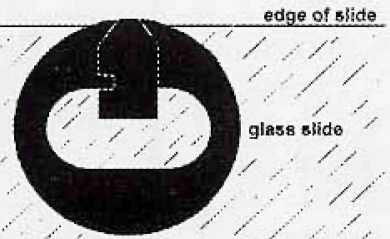

Figure 2. Appearance of the Veco grid after the first fold
Figure 3: Veco grid placed on the edge of glass slide parallel with bottom of notch prior to bending and making the vertical tab to mount the SACT sample 

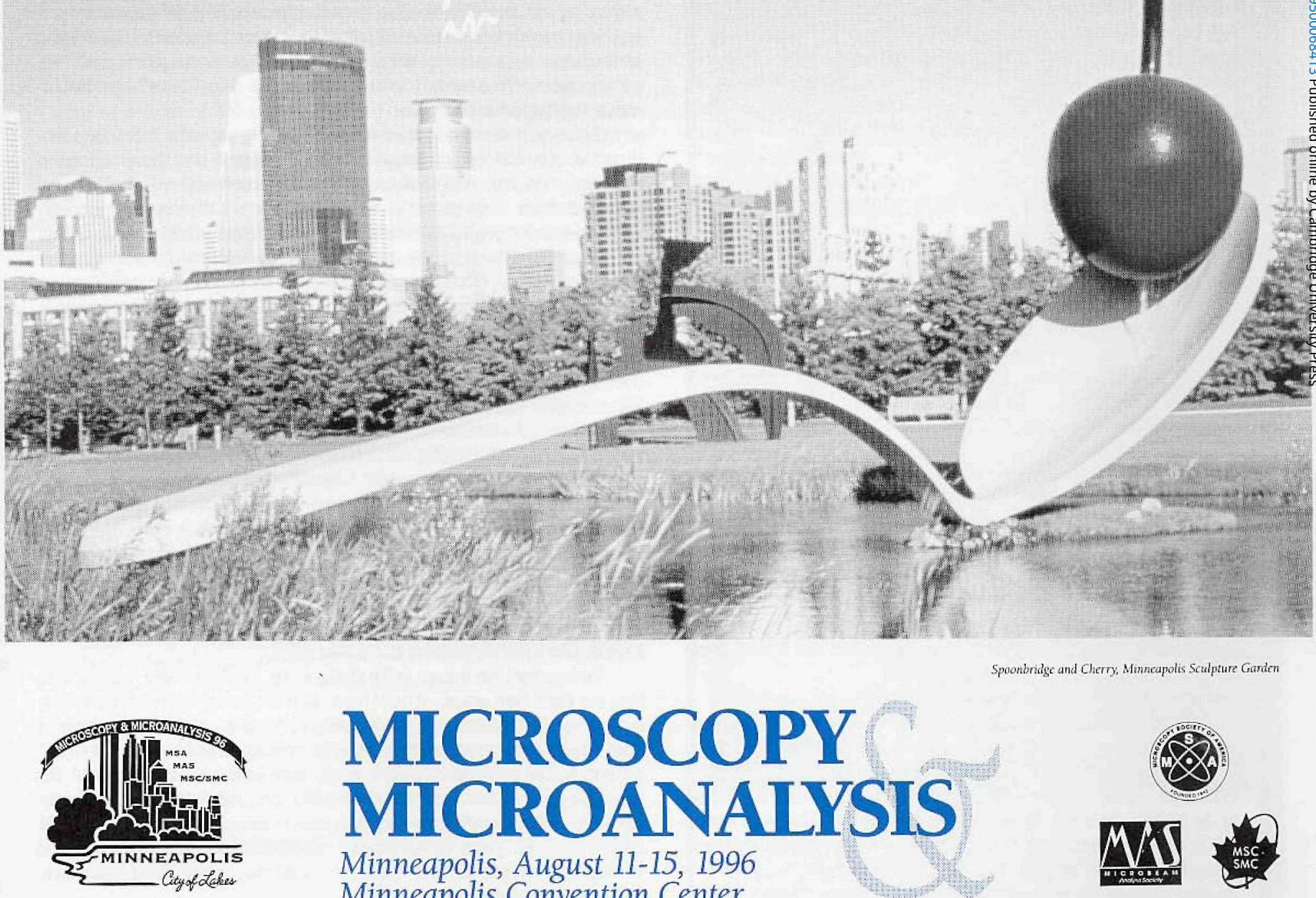

\section{MICROSCOPY MICROANALYSIS}

Minneapolis, August 11-15, 1996

Minneapolis Convention Center

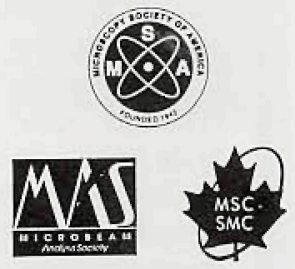

Microscopy Society of America (MSA) - Microbeam Analysis Society (MAS) - Microscopical Society of Canada/Société de Microscopie du Canada (MSC/SMC)

\begin{tabular}{|c|}
\hline INVITED SYMPOSIA \\
\hline $\begin{array}{l}\text { BIOLOGICAL SCIENCES } \\
\text { - Advances in Confocal and Multidimensional Light Microscopy } \\
\text { - Correlative Microstopy: Adwances and Applications } \\
\text { - Microscopic An alysis ol Animals with Altered Gene Expression } \\
\text { - New Labels in Biological Microscopy } \\
\text { - Hight-Resolucion Bialogical Cryo SEM } \\
\text { - Dynamic Organization of the Cell }\end{array}$ \\
\hline $\begin{array}{l}\text { PHYSICAL SCIENCES } \\
\text { - Grain Boundary MicroEngincering } \\
\text { - Microscopy of Modulated Structures and Quasierystals } \\
\text { - Frontiers in Polymer Microscopy and Microanalysis } \\
\text { - Critical Issues in Ceramic Microstructures } \\
\text { - Quantitative HREM Analysis of Pec Fect and Defected Materials } \\
\text { - High-Resolution Field Emission SEM in Materials Research }\end{array}$ \\
\hline IMAGING SCIENCES \\
\hline 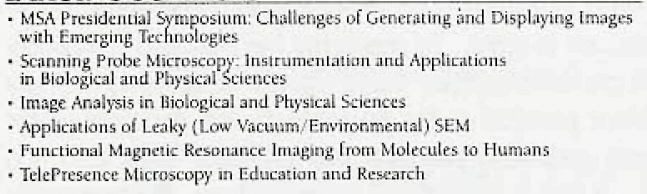 \\
\hline ANALYTICAL SCIENCES \\
\hline 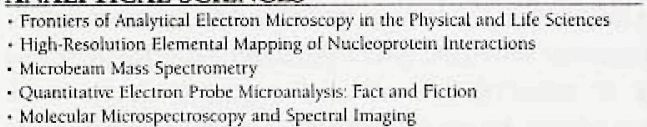 \\
\hline
\end{tabular}

\begin{tabular}{|c|}
\hline $\begin{array}{l}\text { There is good reason to } \\
\text { meet Minneapolis. } \\
\text { There's the Spoonbridge and Cherry. } \\
\text { The Lakes. The Zoo. The Theatre. } \\
\text { The Raptor Center. The Casino. } \\
\text { The Parks. The Twins. Stillwater. } \\
\text { The Planes of Fame Museum. } \\
\text { The Mall of America. } \\
\text { The Science Museum. } \\
\text { And the list just doesn't end. } \\
\text { But the best reason to } \\
\text { meet Minneapolis is the } \\
\text { Meeting in Minneapolis. }\end{array}$ \\
\hline 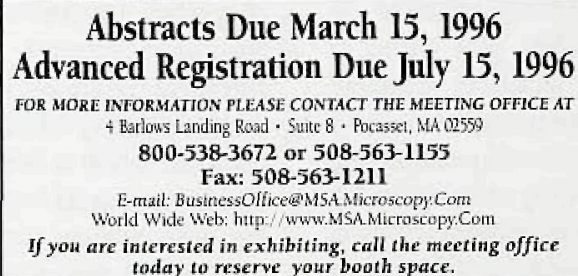 \\
\hline
\end{tabular}
SHORT COURSES
Colloidal Gold Cytorturnistry
Scannuirg Electron Microscopy
Introduction to Digital Imaging
Advanced 1mage Analysis and Image Processing in Microscopy
Atomic Forter Microseopy

\section{PRE-MEEIING WORRSHOPS}

High-Resolution FESEM Imaging of Cells and Macromolecules

Accessing and Using the World Wide Web for Microscopy and Microanalysis

TUTORJAIS
- 3.D Microscopy Using Widefield Deconvolutun
- 3-D Microscopy Using Confocal Microscopy
- The Role of Deconwolution Evaluated
- 3.D Microscopy. Triphte State Losses and
Detector Qe on 3-D Microscopy
- lon Eeam Milling Materials with Appications to TEM Specimen Preparation

\section{OTHER MAJOR PRESENTATIONS}

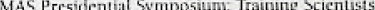

and Enguneers of Tomorrow

- MAS Presidential Awards

MSC SMC G.T. Simon Studem Awards

- MSC SMC Presidential Speaker Awards

- Tech Forum: Moring to Digital Microscom- Is the Time Right?

- Tech Forum Round Table Discussion

OSHA Issue:

Computer Workshop and Sof ware Exchunge

- Public Policy

Project MICRO

Over 250 Commercial Exhibit Booths • Over 500 Scientific Papers • Over 50 Scientific Sessions • Poster Sessions 